\title{
Hypothermia with Osborn Waves in Parkinson's Disease
}

\author{
Yoshihide Sehara
}

\begin{abstract}
Autonomic dysfunction in patients with Parkinson's disease has been recognized since the original description by James Parkinson in 1817. In the present case, an 80-year-old woman who had been diagnosed with Parkinson's disease 3 years earlier (Hoehn and Yahr stage III) was admitted with a few days history of lethargy and bradykinesia. She lived in a heated house and used an electric blanket at night. On examination, her core temperature was $29.7^{\circ} \mathrm{C}$. Her initial ECG showed sinus bradycardia, QT prolongation, and Osborn waves, which disappeared after rewarming. Successful rewarming was achieved with an external rewarming blanket over 12 hours. Follow-up ECG showed resolution of the Osborn waves. In Parkinson's disease, rapidly progressive hypothermia can occur in a well-heated house. Determining a rewarming strategy is a complex but not insurmountable task. In the elderly, the use of careful active external rewarming and a low stress strategy may be recommended.
\end{abstract}

Key words: accidental hypothermia, Osborn wave, Parkinson's disease

(Inter Med 48: 615-618, 2009)

(DOI: 10.2169/internalmedicine.48.1899)

\section{Introduction}

Autonomic dysfunction in patients with Parkinson's disease has been recognized since the original description by James Parkinson in 1817. In Parkinson's disease, both the central and peripheral nervous systems can be affected. Typically, hypothermia-related cases occur after exposure to low ambient temperatures; however, some cases develop in individuals with no history of exposure to a cold environment. In the present case, rapidly progressive hypothermia occurred in a patient living in a well-heated house.

\section{Case Report}

On a cold winter's day in February 2008, an 80-year-old woman was admitted with a few days history of lethargy and bradykinesia. She lived in her heated house and used an electric blanket at night. She dressed herself and ate breakfast by herself even on the day of admission. After breakfast, her movement gradually became impaired. She came to our hospital accompanied by her sister.

The patient had been diagnosed with Parkinson's disease 3 years earlier (Hoehn and Yahr stage III), and was taking carbidopa-levodopa at $40-400 \mathrm{mg} / \mathrm{day}$, pramipexole at 4.5 $\mathrm{mg} /$ day, and selegiline at $5 \mathrm{mg} /$ day. She had a past history of otitis media and hypertension. She did not drink alcohol or smoke tobacco.

On examination, her core temperature was $29.7^{\circ} \mathrm{C}$, blood pressure was $87 / 52 \mathrm{mmHg}$, heart rate was 38 beats/min, and the Glasgow coma scale was 12 . Her lung and cardiac examinations were normal. Neurologic examination revealed akinesia, resting tremor, and mild rigidity of all extremities (predominant on the right side of the body). Her hemoglobin was $12.3 \mathrm{~g} / \mathrm{dL}$, white cells $5 \times 10^{9} / \mathrm{L}$, and platelets $136 \times$ $10^{9} / \mathrm{L}$. Serum chemistries showed sodium $135 \mathrm{mEq} / \mathrm{L}$, potassium $3.96 \mathrm{mEq} / \mathrm{L}$, chloride $107 \mathrm{mEq} / \mathrm{L}$, calcium $9.7 \mathrm{mg} / \mathrm{dL}$, phosphate $3.7 \mathrm{mg} / \mathrm{dL}$, blood urea nitrogen $27.4 \mathrm{mg} / \mathrm{dL}$, creatinine $0.71 \mathrm{mg} / \mathrm{dL}$, and blood glucose $219 \mathrm{mg} / \mathrm{dL}$. Thyroid stimulating hormone was $5.05 \mu \mathrm{IU} / \mathrm{mL}$, free T4 $1.20 \mathrm{ng} / \mathrm{dL}$, and free T3 $2.40 \mathrm{pg} / \mathrm{mL}$. No further analysis for hormones or vitamins was carried out. Urianalysis was unremarkable. Cardiac troponins were negative. Ultrasound cardiography revealed normal cardiac function. Noncontrast head magnetic resonance images and noncontrast head, chest, and abdomen computerized tomograms were unremarkable.

Her initial ECG showed sinus bradycardia, QT prolongation, and Osborn waves $\left(29.7^{\circ} \mathrm{C}\right.$; Fig. 1), which disappeared 

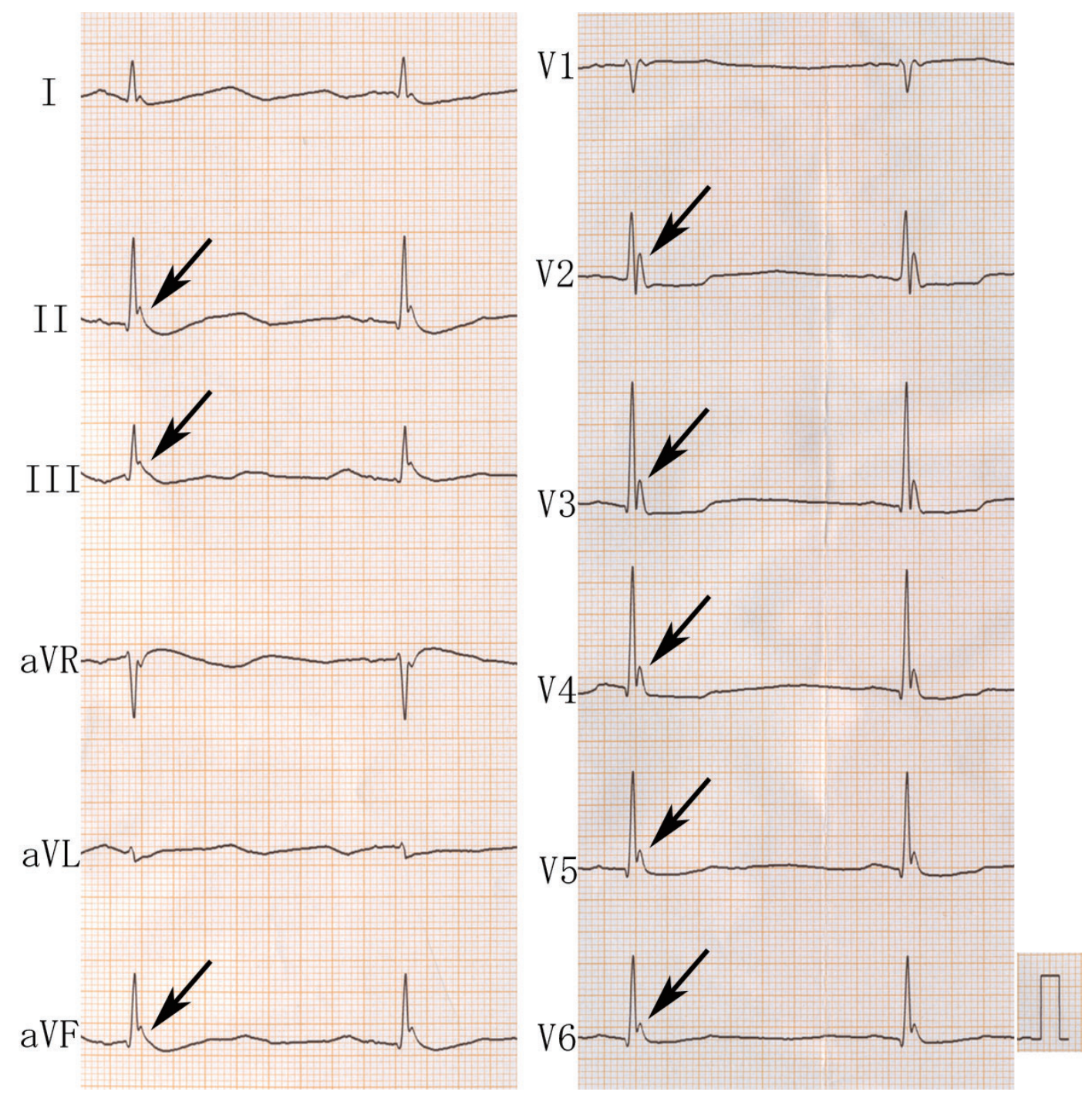

Figure 1. A 12-lead ECG obtained during hypothermia showing sinus bradycardia, Osborn waves (marked with arrows), and a prolonged QT interval (corrected QT interval: $456 \mathrm{~ms}$ ). Her core temperature was $29.7^{\circ} \mathrm{C}$.

after rewarming $\left(36.1^{\circ} \mathrm{C}\right.$; Fig. 2$)$.

Successful rewarming was achieved with an external rewarming pad (Bair Hugger ${ }^{\circledR}$, a heating pad with circulating warmed air inside; Arizant Healthcare Inc., Eden Prairie, $\mathrm{MN})$ over 12 hours, and her vital signs progressively improved; more aggressive rewarming maneuvers were not performed. Follow-up ECG showed resolution of the Osborn waves. Her functional capacity had returned to its previous level by the day after admission. No further episodes of hypothermia have occurred.

\section{Discussion}

The patient had accidental hypothermia on presentation. The most common cause of hypothermia is cold weather exposure. In this case, rapidly progressive hypothermia occurred in a well-heated house.

There are few reported cases of hypothermia in Parkinson's disease (1). Cases of hypothermia due to the involvement of the central nervous system have been reported. For example, the central thermoregulatory ability can be impaired in Parkinson's disease, uremia, multiple sclerosis, and Wernicke's syndrome, and in situations such as stroke, CNS trauma or infection, tumors, limbic encephalitis, or hemorrhage (2-5). Clinical reports on Parkinson's disease have shown abnormal thermoregulation, which consists of heat intolerance and hypothermia (6), attributed to dysfunction of the autonomic nervous system (7). The preoptic hypothalamus controls heat conservation, triggers sympathetic activity, and is activated by the cold stimulation of cutaneous thermoreceptors. Patients with Parkinson's disease often complain of increased sweating of their face, neck, arms and back, and seborrhea on the face and hands (8). This overexpression of sebum has been attributed to hyperactivity of the parasympathetic component of the autonomic nervous system (9). Autonomic neuropathy impairs reflex vasoconstriction. In Parkinson's disease, the hypothalamic thermoregulatory center may also be affected.

Osborn or J waves, originally described in 1953 by Dr. John Osborn, may be present in cases of marked hypother- 




Figure 2. A 12-lead ECG taken after patient rewarming showed the disappearance of Osborn waves and normal repolarization. Her core temperature was $36.1^{\circ} \mathrm{C}$.

mia (10). In the ECG, Osborn waves are seen on the downsloping section of the QRS complex. Compared to other hypothermia-induced ECG abnormalities, such as sinus bradycardia, different supraventricular tachy-brady arrhythmias, QT interval lengthening, and atrioventricular or intraventricular conduction disorders, this phenomenon seems to be the most specific. Most Osborn waves are recorded in the epicardial leads and the leads related to the left ventricle. The list of abnormalities that cause Osborn wave appearance, in addition to the hypothermic condition, include diverse clinical settings like hypercalcemia, cerebral injury, subarachnoidal hemorrhage, myocardial ischemia, and sepsis (11). Recognizing this ECG pseudo-infarct pattern will avoid unwarranted treatment of suspected acute coronary syndrome. The present patient was negative for cardiac troponins throughout her admission.

Hypothermia is defined as a core body temperature of less than $35^{\circ} \mathrm{C}$. Although cutoff points vary, hypothermia can be classified as mild (core body temperature $>32$ and < $35^{\circ} \mathrm{C}$ ), moderate (core body temperature $28-32^{\circ} \mathrm{C}$ ), or severe (core temperature $<28^{\circ} \mathrm{C}$ ) (12). Moderate to severe hypothermia is a medical emergency necessitating maintenance of the airway, breathing, and circulation. Because of the risk of arrhythmia, patients should undergo cardiac monitoring and be transferred gently (13). Deciding on a rewarming strategy is a complex but not insurmountable task. An evidencebased approach to management is severely hampered by the paucity of published randomized clinical trials on the sub- 
ject. Although there is a strong physiologic rationale for using invasive methods to hasten rewarming in arrested patients, faster rewarming has not been proven to reduce mortality (14). The presence of comorbid conditions appears to be a much more consistent predictor of mortality than the initial core temperature (15). In the elderly, the use of careful active external rewarming and a low stress strategy may be recommended.
As far as the research conducted for the patient, based on the fact that other underlying disease is inapparent and the condition of Parkinson's disease has not changed, it seems important to avoid lengthy exposure to a cold environment and to take the body temperature at the earliest possible time when any change is observed to the patient's condition from the aspect of prevention and early detection.

\section{References}

1. Gubbay SS, Barwick DD. Two cases of accidental hypothermia in Parkinson's disease with unusual E.E.G. findings. J Neurol Neurosurg Psychiatry 29: 459-466, 1966.

2. White KD, Scoones DJ, Newman PK. Hypothermia in multiple sclerosis 61: 369-375, 1996.

3. Mallet ML. Pathophysiology of accidental hypothermia. Q J Med 95: 775-785, 2002.

4. Fukushima K, Yazaki M, Kaneko K, et al. Nonparaneoplastic, nonherpetic, limbic encephalitis with sever episodic hypothermia: a case report. Eur Neurol 54: 170-174, 2005.

5. Jacob S, Irani SR, Rajabally YA, et al. Hypothermia in VGKC antibody-associated limbic encephalitis. J Neurol Neurosurg Psychiatry 79: 202-204, 2008.

6. Goetz CG, Lutge W, Tanner CM. Autonomic dysfunction in Parkinson's disease. Neurology 36: 73-75, 1986.

7. Pazo JH, Belforte JE. Basal ganglia and functions of the autonomic nervous system. Cell Mol Neurobiol 22: 645-654, 2002.

8. Hirayama M. Sweating dysfunctions in Parkinson's disease. J
Neurol 253 (suppl 7): 42-47, 2006.

9. Micieli G, Tosi P, Marcheselli S, Cavallini A. Autonomic dysfunction in Parkinson's disease. Neurol Sci 24: 32-34, 2003.

10. Osborn JJ. Experimental hypothermia respiratory and blood $\mathrm{pH}$ changes in relation to cardiac function. Am J Physiol 175: 389398, 1953.

11. Gussak I, Bjerregaard P, Egan TM, Chaitman BR. ECG phenomenon called the J wave. J Electrocardiol 28: 49-58, 1995.

12. Aslam AF, Aslam AK, Vasavada BC, Khan IA. Hypothermia: evaluation, electrocardiographic manifestation, and management. Am J Med 297-231, 2006.

13. Biem J, Koehncke N, Classen D, Dosman J. Out of the cold: management of hypothermia and frostbite. CMAJ 168: 305-311, 2003.

14. Kempainen RR, Brunette DD. The evaluation and management of accidental hypothermia. Respir Care 49: 192-205, 2004.

15. Muszkat M, Durst RM, Ben-Yehuda A. Factors associated with mortality among elderly patients with hypothermia. Am J Med 113: 234-237, 2002.

(C) 2009 The Japanese Society of Internal Medicine http://www.naika.or.jp/imindex.html 